TP Periodica Polytechnica Mechanical Engineering

62(1), pp. 65-73, 2018

https://doi.org/10.3311/PPme.11416

Creative Commons Attribution (i)

RESEARCH ARTICLE

\section{Thermodynamic and Numerical}

Analysis of Tangentially Fired Boiler

for Increasing Efficiency and Reducing Environmental Pollution

\author{
Navid Abdollahi ${ }^{*}$, Ramin Haghighi-Khoshkhoo ${ }^{1}$
}

Received 24 August 2017; accepted after revision 13 November 2017

\begin{abstract}
The evaluation of heat transfer and fluid mechanics mechanisms to increase the thermal efficiency and combustion quality in heavy industries, such as power plants, are important and significant issues in the field of engineering sciences, which can lead to significant advances. In this regard, the present paper has been developed with thermodynamic and numerical simulations of the MONTAZER GHAEM Power Plant boiler to study the increase in efficiency and reduce environmental pollution. Also in this research, the results of practical tests have been used to verify the simulations. The thermodynamic simulation results show that the required fuel consumption of the burners in current operating conditions is not $9.1 \mathrm{~kg} / \mathrm{s}$, but it is $8.1 \mathrm{~kg} / \mathrm{s}$. The low efficiency of the set, which leads to the injection of more than the required amount of fuel to the boiler, cause the non-corresponding power generation for injected fuel, which results in the reduction of the plant thermal efficiency from $36.4 \%$ to $33.9 \%$. The results of computational fluid dynamics show that the lightness of natural gas combustion products and, the no-flow accumulation in the lower parts of the furnace, reduce the produced steam, which results in power loss at the exit. Numerical results also show that the highest rate of $\mathrm{NO}_{X}$ production occurs near the burners due to the high flame temperature and high oxygen mass fraction and consequently, the non-uniform distribution of heat in the furnace.
\end{abstract}

\section{Keywords}

tangentially fired boiler, thermodynamic Simulation, numerical simulation, combustion, CFD

\footnotetext{
${ }^{1}$ Department of Energy Systems,

Faculty of Mechanical and Energy Engineering,

Shahid Beheshti University (SBU),

P.O.B. 16765-1719, Tehran, Iran

"Corresponding author, e-mail: n.abdollahi72@yahoo.com
}

\section{Introduction}

Tangentially fired boilers are mainly used in the power generation industry due to the proper flame distribution and uniform heat flux. These boilers are characterized by the shape of the furnace and the location of fuel and air entrances. They usually have four faces and four corners that fuel and air are supplied from these corners. During the operation due to the flow circulation, the flames are tangentially connected and create a virtual circle called the target circle in the center of the furnace. McKenty et al. [1] developed a model for a dual fuel tangentially fired boiler using computational fluid dynamics and evaluated the flow behavior and $\mathrm{NO}_{\mathrm{x}}$ production in the furnace. Modlinski [2] developed a model to retrofit an auxiliary boiler using replacement of current burners to a new tangent one using computational fluid dynamics. The purpose of this modeling is to analyze the flow and combustion performance in the furnace. Fang et al. [3] developed the computational fluid dynamics model of multi-fuel combustion in a 200 MW tangentially fired utility boiler. They concluded that multi-fuel combustion is one of the options that can be used to improve combustion behavior and reduce pollutant emissions. Depman [4] updated the computational fluid dynamics model of the industrial boilers of the Iowa University, which had previously been developed. He upgraded boundary conditions and flow models of simulation to accurate, realistic simulations. Shi et al. [5] evaluated $\mathrm{NO}_{\mathrm{X}}$ production in a $300 \mathrm{MW}$ boiler using computational fluid dynamics modeling. They concluded that retrofit of the combustion system not only reduced the total $\mathrm{NO}_{\mathrm{x}}$ production concentration at the boiler output but also affected the $\mathrm{NO}_{\mathrm{X}}$ formation region in the furnace. Tang et al. [6] developed a numerical model for simulating flow and combustion indices in a $200 \mathrm{MW}$ tangentially fired boilers. They investigated wall steam tubes overheating problem and the effect of fuel input percentage on the furnace wall temperature. Sabounchi et al. [7] simulated a 200 MW boiler of MONTAZERI Power Plant in Isfahan using computational fluid dynamics. They examined the effect of the central air to secondary air ratio in the burners on boiler performance. Sa'adati et al. [8] have tried to investigate the effect of the angle and speed of sputtering a solid fuel on combustion 
parameters such as flame shape, temperature distribution, and $\mathrm{CO}$ emission rate. They showed that the angle and the rate of air and fuel injection substantially alter the flame situation and the combustion products.

MONTAZER GHAEM Plant is a steam power plant in Iran that located at 40 kilometers from Tehran. In 1967, the contract for the construction of four units of this, each unit with a 156.25 MW power, was completed between the Ministry of Energy and the General Electric Company [9].

Due to the impossibility of using natural gas at the time of plant unit's delivery, only the operation of the power plant with heavy fuel oil has been tested and delivered. But now, concerning environmental issues, natural gas is used as an alternative fuel. In the case of the commissioning of a power plant with natural gas, it is observed that the output power of each boiler unit is reduced from nominal 156.25 MW to $130 \mathrm{MW}$, and if the fuel flow rate increases to more than the nominal value, the generated power increases by up to $140 \mathrm{MW}$. Under these circumstances, with the maximum tilt angle $\left(-30^{\circ}\right)$, superheater tubes overheat and disappear. On the other hand, pollutants in the stack outlet will be more than the standard value. Therefore the power plant's management to reduce the pollutants and, thermal stresses introduced into the superheater tubes, increases the boiler air flow rate up to $16 \%$ of the stoichiometric value. Increasing the boiler air flow rate will reduce the pollutants to the limit, but will reduce the generated power by up to $135 \mathrm{MW}$. Therefore, the present paper is developed with the thermodynamic and numerical simulations of MONTAZER GHAEM Power Plant boiler to solve the problem of power loss and reduction of environmental pollutants. Also in this study, to verify the simulations, the results of practical tests will be used [10].

\section{Thermodynamic Simulation}

To overall evaluate of the Power Plant, its thermodynamic cycle must be investigated.
One of the best tools to simulate thermodynamic cycles is the THERMOFLOW software package. This software, as one of the complete software tools in the field of design and analysis of power plants, can perform different stages of a power plant design including thermodynamic analysis and equipment engineering analysis. THERMOFLOW analyzes problems with the Zero-Dimension method and therefore has a high response speed and stability in computing. To model MONTAZER GHAEM Power Plant thermodynamic cycle, THERMOFLEX module of THERMOFLOW software package will be used. The simulated cycle of unit 4 of the MONTAZER GHAEM Power Plant in THERMOFLEX is shown in Fig. 1.

\section{Numerical Simulation}

Since the flow inside the boiler is combustible and turbulent, so the governing equations for simulating this kind of flow are Mass Conservation, Momentum Conservation, Energy, Turbulence, Species Conservation, Combustion and, Radiation. Each of these equations as follows [6]:

\subsection{Continuity equation (Mass Conservation)}

$$
\nabla \cdot(\rho \vec{v})=0
$$

\subsection{Momentum equation}

$$
\nabla \cdot(\rho \vec{v} \vec{v})=-\nabla_{p}+\nabla \cdot(\overline{\bar{\tau}})+\rho \bar{g}+\bar{F}
$$

And $\overline{\bar{\tau}}$ is a stress tensor and which is given by the following:

$$
\overline{\bar{\tau}}=\mu\left[\left(\nabla \vec{v}+\vec{v}^{T}\right)-\frac{2}{3} \nabla \cdot \vec{v} I\right]
$$

By the Reynolds time averaging method, mass and momentum equations converted to Reynolds averaged Navier-Stokes equations (RANS) as follows:

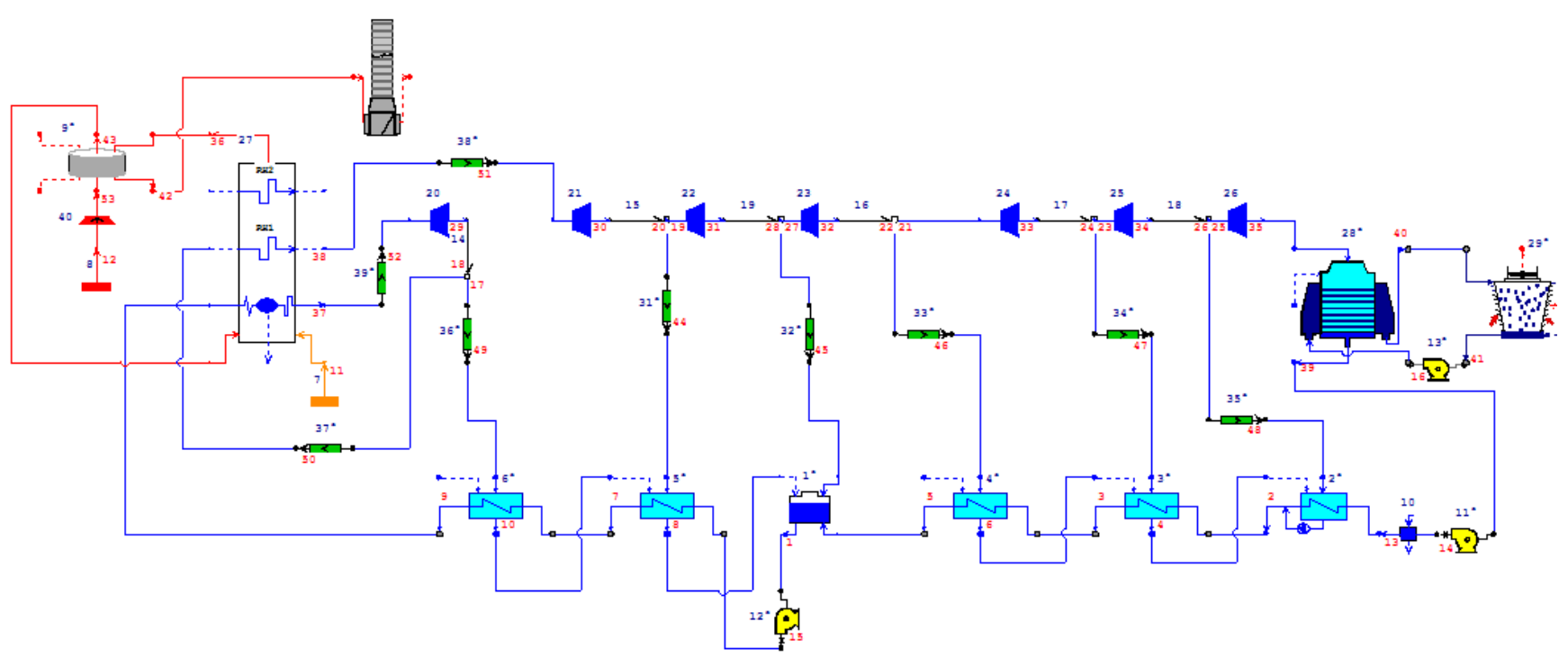

Fig. 1 Simulated cycle of unit 4 of MONTAZER GHAEM Power Plant in THERMOFLEX 


$$
\begin{aligned}
\frac{\partial}{\partial x_{j}}\left(\rho u_{i} u_{j}\right)= & -\frac{\partial p}{\partial x_{i}}+\frac{\partial}{\partial x_{i}}\left[\mu\left(\frac{\partial u_{i}}{\partial x_{j}}+\frac{\partial u_{j}}{\partial x_{i}}-\frac{2}{3} \sigma_{i j} \frac{\partial u_{I}}{\partial x_{I}}\right)\right] \\
& +\frac{\partial}{\partial x_{j}}\left(-\rho \overline{u_{i}^{\prime} u_{j}^{\prime}}\right)
\end{aligned}
$$

These equations are given for averaged variables only, and, without the need to solve turbulence, impose their effects on the solution field.

In the Eq. (4), the Reynolds stresses that are unknown, can be related to the velocity gradient by Boussinesq approximation as follows:

$$
-\rho \overline{u_{i}^{\prime} u_{j}^{\prime}}=\mu_{t}\left(\frac{\partial u_{i}}{\partial x_{j}}+\frac{\partial u_{j}}{\partial x_{i}}\right)-\frac{2}{3}\left(\rho k+\mu_{t} \frac{\partial u_{k}}{\partial x_{k}}\right) \sigma_{i j}
$$

\subsection{Energy equations}

The energy equation is represented as follows:

$$
\nabla \cdot[\vec{v}(\rho E+P)]=\nabla \cdot\left[k_{e f f} \nabla T-\sum_{j} h_{j} \vec{J}_{j}+\left(\overline{\bar{\tau}}_{e f f} \cdot \vec{v}\right)\right]+S_{h}
$$

Where $E$ is:

$$
E=h-\frac{p}{\rho}+\frac{v^{2}}{2}
$$

Where sensible enthalpy $h$ for the ideal gas is equal to:

$$
h=\sum_{j} Y_{j} h_{j}
$$

And the sensible enthalpy for the forming particles is defined by integral relation as follows:

$$
h_{j}=\int_{298.15}^{T} C_{p, j} d T
$$

\subsection{Turbulence Model}

The purpose of the turbulent flow modeling is to determine the terms such as Reynolds stress, turbulent thermal flux by relating these values to the mean of flow quantities, especially the average gradient of the flow variables [11]. In this regard, in the present paper, the Realizable $k-\varepsilon$ model is used for turbulent flow modeling. The turbulence energy equation $(k)$ and the turbulent dissipation rate $(\varepsilon)$ as follows respectively [6]:

$$
\begin{gathered}
\frac{\partial}{\partial t}(\rho k)+\frac{\partial}{\partial x_{i}}\left(\rho k u_{j}\right)=\frac{\partial}{\partial x_{i}}\left[\left(\mu+\frac{\mu_{t}}{\sigma_{k}}\right) \frac{\partial k}{\partial x_{i}}\right] \\
-\rho \overline{u_{i}^{\prime} u_{j}^{\prime}} \frac{\partial u_{j}}{\partial x_{i}}+\beta g_{i} \frac{\mu_{t}}{\operatorname{Pr}_{t}} \frac{\partial T}{\partial x_{i}}-\rho \varepsilon-Y_{M}+S_{K} \\
\mu_{t}=C_{\mu} \rho \frac{k^{2}}{\varepsilon}
\end{gathered}
$$

$$
\begin{aligned}
\frac{\partial}{\partial t}(\rho \varepsilon)+\frac{\partial}{\partial x_{j}}\left(\rho \varepsilon u_{j}\right) & =\frac{\partial}{\partial x_{j}}\left[\left(\mu+\frac{\mu_{t}}{\sigma_{\varepsilon}}\right) \frac{\partial \varepsilon}{\partial x_{i}}\right] \\
& +\rho C_{1} S-\rho C_{2} \frac{\varepsilon^{2}}{k+\sqrt{v \varepsilon}}+C_{1 \varepsilon} \frac{\varepsilon}{k} C_{3 \varepsilon} G_{b}+S_{\varepsilon}
\end{aligned}
$$

Which:

$$
\begin{gathered}
C_{1}=\max \left(0.43, \frac{\eta}{\eta+5}\right) \\
\eta=S \frac{k}{\varepsilon} \\
S=\sqrt{2 S_{i j} S_{i j}} \\
S_{i j}=\frac{1}{2}\left(\frac{\partial u_{j}}{\partial x_{i}}+\frac{\partial u_{i}}{\partial x_{j}}\right)
\end{gathered}
$$

\subsection{Species Conservation Equation}

The conservation equation of each species as follows:

$$
\nabla *\left(\rho \bar{v} Y_{i}\right)=-\nabla * \vec{J}_{i}+R_{i}
$$

$$
\vec{J}_{i}=-\left(\rho D_{i, m}+\frac{\mu_{t}}{S c_{t}}\right) \nabla Y_{i}-D_{T, i} \frac{\nabla T}{T}
$$

\subsection{Combustion model}

The governing equations for combustion in turbulent flows are Navier-Stokes Reacting equations which are very precise on their own. However, since in turbulent flows all parameters of the turbulence flow are not fully known and accessible in detail, and in fact, these variables are modeled in some way, it is not possible to consider and solve the turbulent flow combustion equations directly. Therefore, for such flows, moderated combustion models or FANS ${ }^{1}$ are used [8]. Eddy dissipation model and eddy dissipation concept are of this type.

The Eddy-Dissipation Concept (EDC) is used to model the Turbulence-Chemistry Interaction. The Eddy-Dissipation Concept model is an extension of the eddy-dissipation model to include detailed chemical mechanisms in turbulent flows [12]. The source terms in the conservation equation for the mean species $i$ modeled as:

$$
R_{i}=\frac{\rho\left(\xi^{*}\right)^{2}}{\tau^{*}\left[1-\left(\xi^{*}\right)^{3}\right]}\left(Y_{i}^{*}-Y_{i}\right)
$$


Which:

$$
\begin{gathered}
Y_{i}=\left(\xi^{*}\right)^{3} Y_{i}^{*}+\left(1-\left(\xi^{*}\right)^{3}\right) Y_{i}^{0} \\
\xi^{*}=C_{\xi}\left(\frac{v \varepsilon}{k^{2}}\right)^{1 / 4}
\end{gathered}
$$

It is assumed that reactions occur in fine structures [12]. Residence time scale $\left(\tau^{*}\right)$ of these structures as follow:

$$
\tau^{*}=C_{\tau}\left(\frac{v}{\varepsilon}\right)^{1 / 2}
$$

Also, the species considered in the natural gas include methane, ethane, and propane. The reactions that are taken into account for these species are shown in Table 1:

Table 1 Combustion species with reaction mechanisms

\begin{tabular}{lc}
\hline Species & Reactions \\
\hline Methane & $\mathrm{CH}_{4}+\frac{3}{2} \mathrm{O}_{2} \rightarrow \mathrm{CO}+2 \mathrm{H}_{2} \mathrm{O}$ \\
& $\mathrm{CO}+\frac{1}{2} \mathrm{O}_{2} \rightarrow \mathrm{CO}_{2}$ \\
Ethane & $\mathrm{C}_{2} \mathrm{H}_{6}+\frac{7}{2} \mathrm{O}_{2} \rightarrow 2 \mathrm{CO}_{2}+3 \mathrm{H}_{2} \mathrm{O}$ \\
& $\mathrm{C}_{3} \mathrm{H}_{8}+\frac{7}{2} \mathrm{O}_{2} \rightarrow 3 \mathrm{CO}+4 \mathrm{H}_{2} \mathrm{O}$ \\
Propane & $\mathrm{CO}+\frac{1}{2} \mathrm{O}_{2} \rightarrow \mathrm{CO}_{2}$ \\
\hline
\end{tabular}

\subsection{Radiation model}

Radiation is the most important way of transferring heat from the flame to the surrounding environment due to its very high temperature. In general, the modeling of volumetric radiation in a three-dimensional space requires a very high computational cost and the radiation equation for the each of the cells and in all three-dimensional directions (angles of a sphere) in to be solved. In order to reduce the computational cost and their usability, various models have been proposed that are suitable for each case.

Both DO, and P1 models have been used in previous studies to model radiation in the furnaces, but $\mathrm{P} 1$ is one of the simplest and most powerful radiation models for the combustion process in the furnaces [13], which is used in the present simulation. Radiation heat flux in this model is a function of radiation intensity, and its relation is expressed as follows [6]:

$$
q_{r}=-\frac{1}{3\left(a+\sigma_{s}\right)-C \sigma_{s}} \nabla G
$$

The transportation equation for incident radiation $G$ is:

$$
\begin{gathered}
\nabla(\nabla \Gamma G)-a G+4 a n^{2} \sigma T^{4}=S_{G} \\
-\nabla q_{r}=a G-4 a n^{2} \sigma T^{4}
\end{gathered}
$$

\subsection{Pollution model}

Three type of $\mathrm{NO}_{\mathrm{X}}$ formation includes: thermal $\mathrm{NO}_{\mathrm{X}}$, fuel $\mathrm{NO}_{X}$ and, prompt $\mathrm{NO}_{X}$ are modeled. In [7] stated that in the natural gas combustion, the contribution of thermal $\mathrm{NO}_{\mathrm{X}}$ formation to total $\mathrm{NO}_{\mathrm{X}}$ emission is about $95 \%$. Due to its high value, only this type is described here. The thermal $\mathrm{NO}_{\mathrm{X}}$ modeling as a post-processing process is performed after the calculation of flow convergence by the two steps Zeldovich mechanism and extended Zeldovich mechanism [5]. The following equation gives the production rate using this mechanism:

$$
\frac{d[N O]}{d t}=2[O]\left\{\frac{k_{1}\left[N_{2}\right]-\frac{k_{-1} k_{-2}[N O]^{2}}{k_{2}\left[O_{2}\right]}}{1+\frac{k_{-1}[N O]}{k_{2}\left[O_{2}\right]+k_{3}[O H]}}\right\}
$$

\subsection{Solution method}

All simulations are considered as a steady state. The governing equations are solved segregated by using iteration solving method using the ANSYS Fluent 14.0 software on a parallel processing system with eight cores. All of these equations will be solved in the integral form and with finite volume method. The thermal absorption coefficients of the combustion gases are calculated by the Weighted Sum of Gray Gases Method (WSGGM). By using the temperature dependent properties model, simulations accuracy increase. The SIMPLE algorithm was applied to consider the coupling of velocity and pressure fields. The conservation equations of the gas phase were solved with successive under-relaxation iterations until the solution satisfied residuals, which were set to $1 \mathrm{e}-6$ for the energy and radiation, 1e-5 for pollutants equations and, 1e-3 for other equations. Also, the amount of temperature on the superheater inlet cross-section is selected as the monitored parameter, which after it is fixed the solution iteration is stopped.

\section{Boundary conditions and geometric specifications}

MONTAZER GHAEM Power Plant boiler has a reheat circuit with a natural water circulation. In this furnace, 12 gas burners are located on three floors and four corners. The required air to combust is supplied by two Forced Draft fan and then passes through two Ljungstroms and preheated. Water-walls are located on the side walls $[9,14]$. The temperature and emissivity of the furnace walls are considered constant and equal to $327^{\circ} \mathrm{C}$ and 0.69 respectively. Fuel properties are shown in Table 2, and some of the boiler technical specifications are listed in Table 3.

Burners in the MONTAZER GHAEM Power Plant boiler have the ability to change vertically between the angles of $\pm 30^{\circ}$. This angle is measured from the horizon. Burners are installed in a horizontal plane with an angle of about 39 degrees. The existence of angle in the flat plate will create the circulation flow in the furnace which increases the combustion efficiency. Burner details and boiler geometry are shown in Fig. 2 and Fig. 3 respectively. 
Table 2 Fuel properties [15]

\begin{tabular}{lll}
\hline Characteristic & Result & Unit \\
\hline $\mathrm{C}_{1}$ & 86.608 & mole $\%$ \\
$\mathrm{C}_{2}$ & 4.4958 & mole \% \\
$\mathrm{C}_{3}$ & 1.2194 & mole $\%$ \\
$\mathrm{C}_{4}$ & 0.4772 & mole \% \\
$\mathrm{C}_{5}$ & 0.1908 & $\mathrm{~mole} \%$ \\
$\mathrm{C}_{6}$ & 0.0742 & $\mathrm{~mole} \%$ \\
$\mathrm{C}_{7}$ & 0.0212 & $\mathrm{~mole} \%$ \\
$\mathrm{CO}_{2}$ & 0.9755 & $\mathrm{~mole} \%$ \\
$\mathrm{~N}_{2}$ & 5.9379 & $\mathrm{~mole} \%$ \\
Net Heat Value & 34.21 & $\mathrm{MJ} / \mathrm{m}^{3}$ \\
Density & 0.7794 & $\mathrm{~kg} / \mathrm{m}^{3}$ \\
Average Molecular Weight & 18.38 & $\mathrm{~g} / \mathrm{mol}$ \\
\hline
\end{tabular}

Table 3 Some of the boiler technical specifications [14]

\begin{tabular}{lll}
\hline Characteristic & Result & Unit \\
\hline Ambient pressure & 87.842 & $\mathrm{kPa}-\mathrm{a}$ \\
Furnace pressure & 3.6081 & $\mathrm{kPa}-\mathrm{g}$ \\
Excess air & 15.9 & $\%$ \\
Inlet air flow rate & 158.7 & $\mathrm{~kg} / \mathrm{s}$ \\
Inlet air temperature & 194 & ${ }^{\circ} \mathrm{C}$ \\
Fuel flow rate & 9.1 & $\mathrm{~kg} / \mathrm{s}$ \\
Fuel Temperature & 19.52 & ${ }^{\circ} \mathrm{C}$ \\
\hline
\end{tabular}

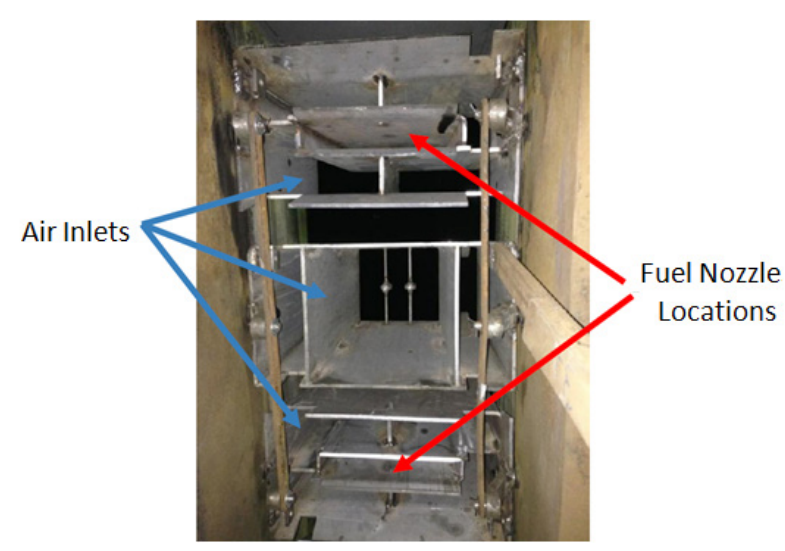

Fig. 2 Burner details

Build a high-quality grid in this great body requires geometry to be zoned. For this purpose, the entire boiler geometry by the ANSYS Gambit software divided into 33 regions, and the main aim of this work is, to fragment the grid in fields that have high gradient velocity and temperature to obtain the correct results. Mesh sensitivity study was conducted between two networks with an approximate size of 273,000 and 1,270,000 cells to achieve accurate results. The simulation error of the temperature on the superheater inlet cross-section is $8.6 \%$ and $2.8 \%$, respectively. Due to the limited capability of the processor used, the grid refining is not feasible more than this and the second one is used for analysis.

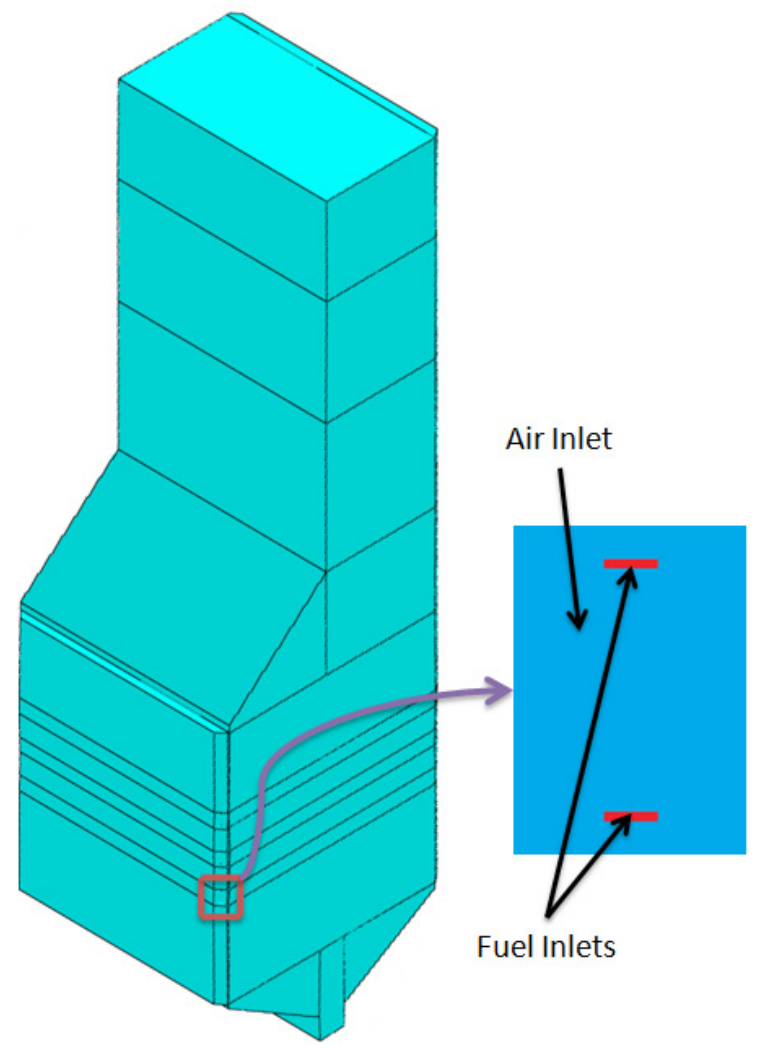

Fig. 3 Computational domain

\section{Results and discussions}

The results of thermodynamic and numerical simulations of the MONTAZER GHAEM Power Plant are presented below.

\subsection{Thermodynamic simulation}

The thermodynamic results obtained from this simulation (such as power, temperature, pressure, etc.) are authentic and accurate, but one of the biggest problems in the THERMOFLOW software simulations is that the combustion process is considered to be complete. Simulated MONTAZER GHAEM power plant boiler stack is shown in Fig. 4. As it is shown, only complete combustion products containing carbon dioxide, water vapor, oxygen, and nitrogen are present in the stack, and no trace of pollutants including nitrogen oxides is observed. However, in real combustion, which is incomplete combustion, other compounds such as carbon monoxide, nitrogen oxides and soot are also produced. Therefore, due to the inability of THERMOFLOW to model incomplete combustion and predict pollutants, other software that can model real combustion will be used.

\subsection{Numerical simulation}

As shown in Fig. 5 the rotating flow pattern was created in the furnace center, and the combustion process (due to the maximum temperature of the region) occurs during this vortex. In Fig. 6 it is also observed that, with the maximum torch tilt angle, the existence of the flow vectors in the lower parts of the furnace is still less, and the main stream accumulation is in the 


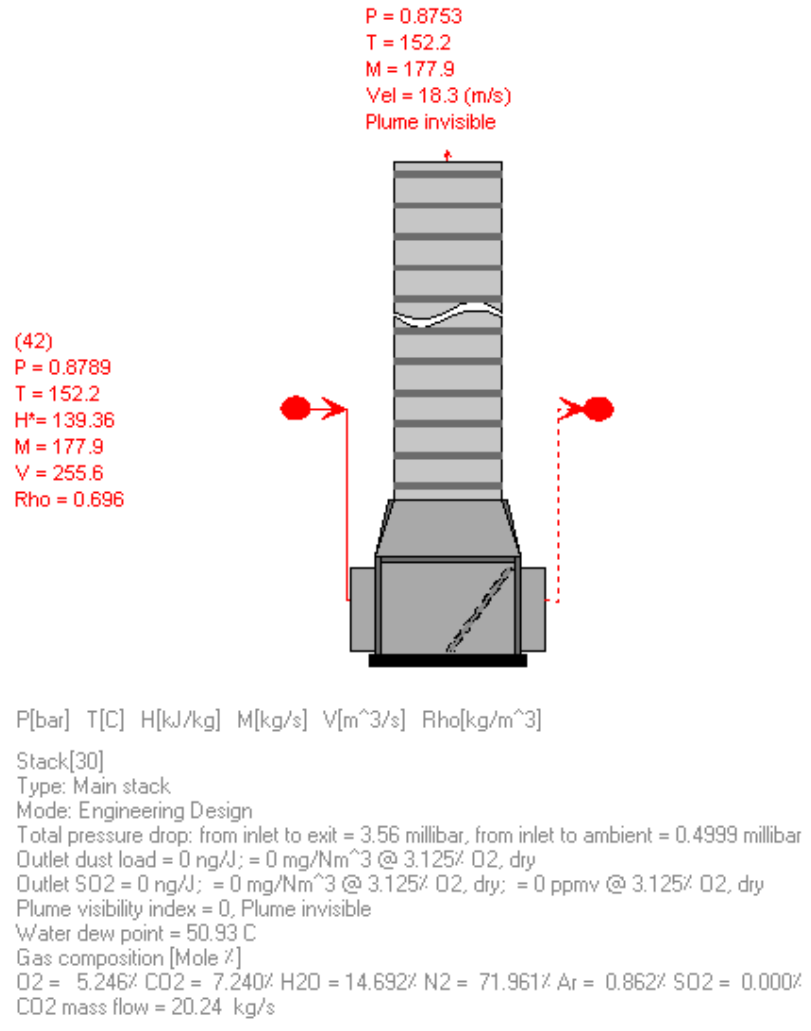

Fig. 4 Simulated boiler stack in THERMOFLEX

central region of the furnace. Since the combustion process is not premixed, air and fuel mixing take a little time, and Ignition will be done after small delay as shown in Fig. 7.

The temperature contours in the first-floor burners cross section shown as a sample of all cross sections in Fig. 8. Also mass fraction contours of all species, including $\mathrm{CO}, \mathrm{O}_{2}$, etc. can be displayed in entire of the boiler, however, due to the importance of NO as one of the pollutants, only the contours of this compound in the sample cross section are shown in a Fig. 9.

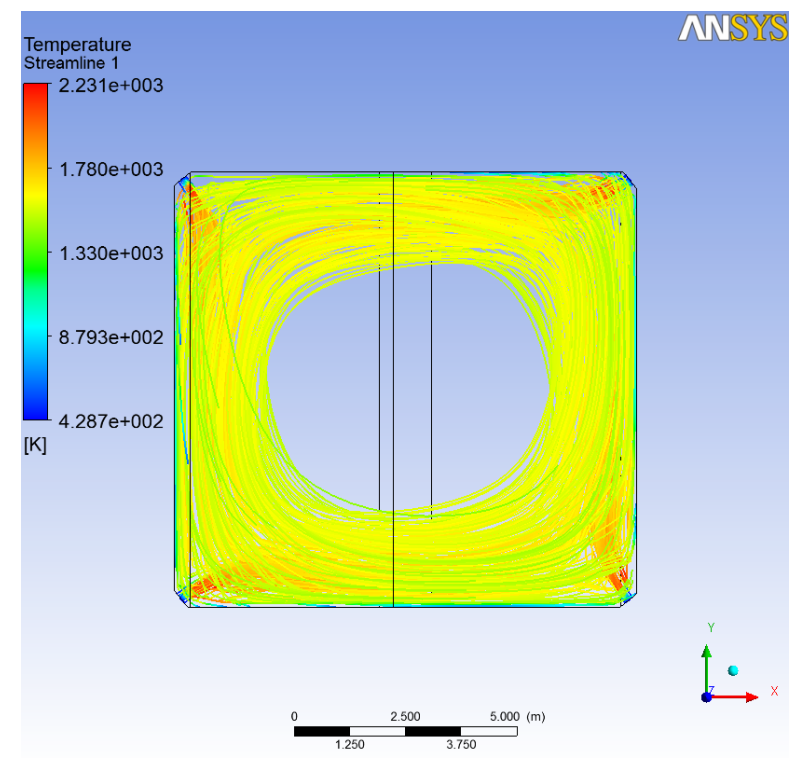

Fig. 5 Rotating flow pattern in horizontal plane in furnace

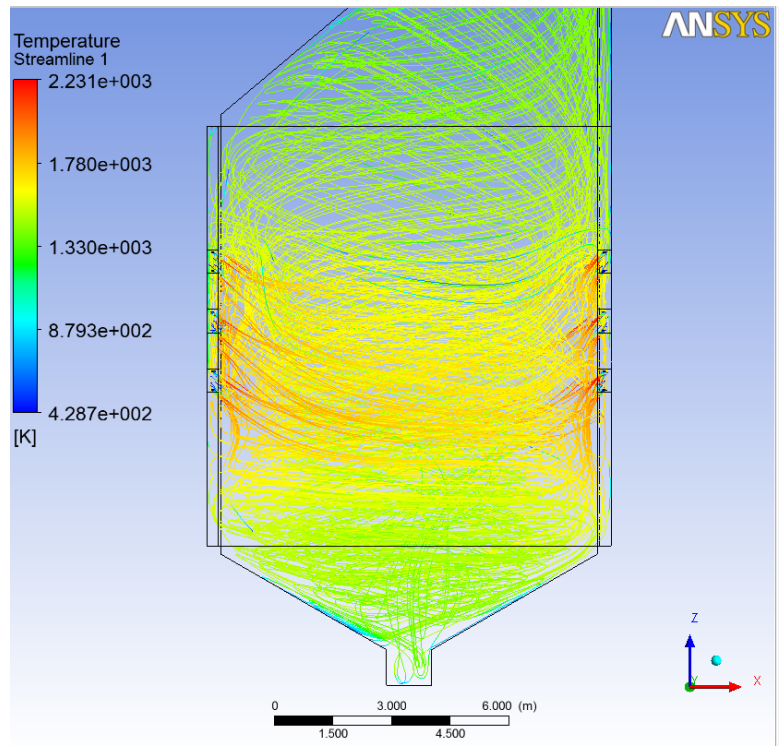

Fig. 6 Flow pattern in side view

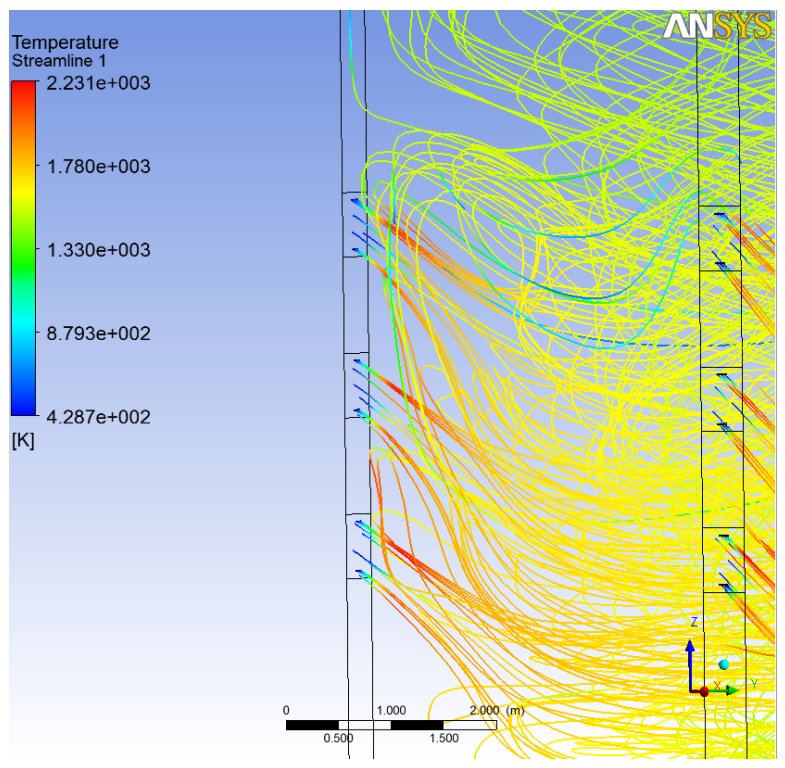

Fig. 7 Ignition delay near burners

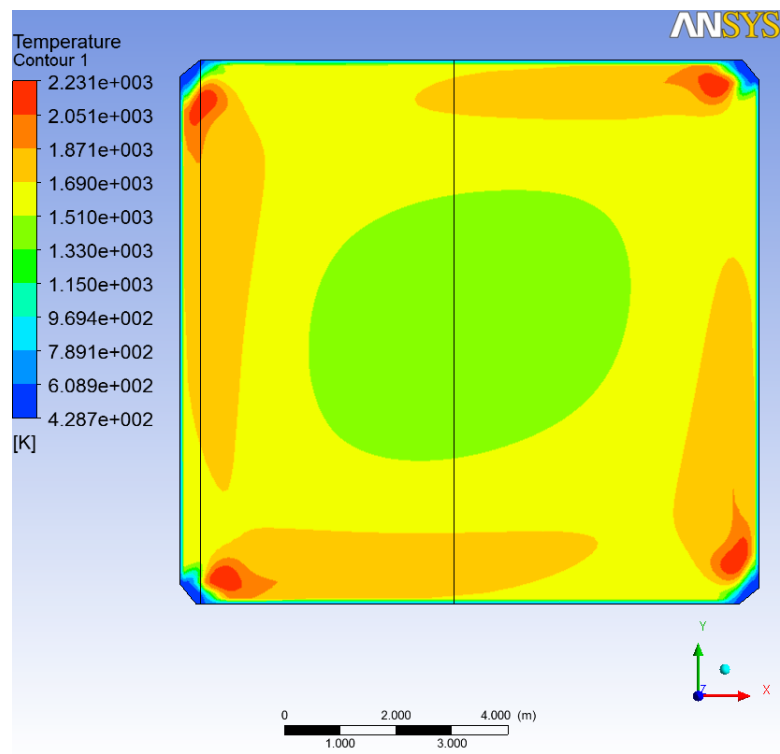

Fig. 8 Temperature contours in the first row burners cross section 


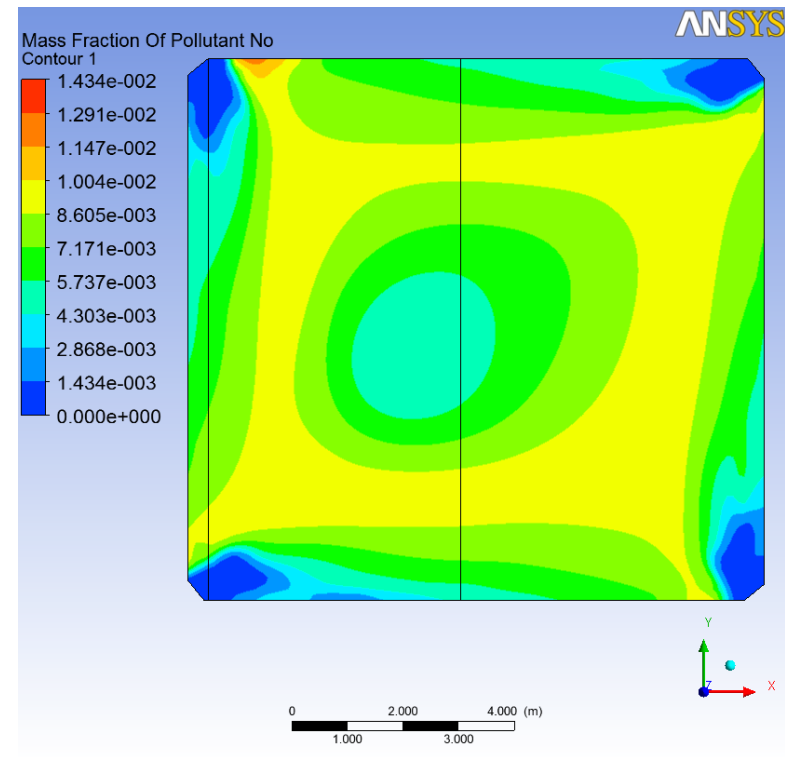

Fig. 9 NO mass fraction contours in the first row burners cross section

Measured values from practical tests [15] are compared with numerical and thermodynamic simulation's results as shown in Table 4.

Table 4 Measured values in comparison to simulated values

\begin{tabular}{lllll}
\hline Parameter & Unit & $\begin{array}{l}\text { THERMOFLOW } \\
\text { result }\end{array}$ & $\begin{array}{l}\text { CFD } \\
\text { result }\end{array}$ & $\begin{array}{l}\text { Measured } \\
\text { values }\end{array}$ \\
\hline Generated power & $\mathrm{kW}$ & 135322 & - & 135000 \\
Plant efficiency & $\%$ & 36.42 & - & 33.86 \\
Fuel consumption & $\mathrm{kg} / \mathrm{s}$ & 8.1 & 9.1 & 9.1 \\
NO emission & $\mathrm{ppm}$ & - & 435 & 103 \\
$\mathrm{CO}$ emission & $\mathrm{ppm}$ & - & 102 & 135.5 \\
$\mathrm{O}_{2}$ emission & $\mathrm{mole} \%$ & 5.246 & 2.78 & 2.61 \\
\hline
\end{tabular}

The measured values indicate that the $\mathrm{CO}$ and $\mathrm{NO}_{\mathrm{X}}$ emissions are appropriate for current operating conditions of the plant, which is due to excessive excess air percentages. The presence of oxygen in combustion products is also a confirmation of this. The thermodynamic simulation results show that the required fuel consumption of the burners in current operating conditions is not $9.1 \mathrm{~kg} / \mathrm{s}$, but it is $8.1 \mathrm{~kg} / \mathrm{s}$. Since the main stream pressure and, temperature and its flow rate at the boiler output are certain and constant, the THERMOFLOW software makes calculations based on the thermal energy of the fuel, so that this pressure and temperature to be provided. In other words, while the $9.1 \mathrm{~kg} / \mathrm{s}$ natural gas is injected into the boiler as fuel, only $8.1 \mathrm{~kg} / \mathrm{s}$ is consumed, and the rest is unburned. The low efficiency of the set, which leads to the injection of more than the required amount of fuel to the boiler, cause the non-corresponding power generation for injected fuel, which results in the reduction of the plant thermal efficiency from $36.4 \%$ to $33.9 \%$. The CFD results show that the lightness of natural gas combustion products and, consequently the no-flow accumulation in the lower parts of the furnace, reduce the generated steam in the boiler, which results in power loss at the exit. Numerical results also show that the highest rate of $\mathrm{NO}_{\mathrm{x}}$ production is near the burners due to the high flame temperature and high oxygen mass fraction and consequently, the non-uniform distribution of heat in the furnace and about three times the average value in the center.

Nowadays, burner manufacturers in their new torches use a mechanism such as the $\mathrm{LNI}^{2}$ to reduce $\mathrm{NO}_{\mathrm{X}}$ emissions. This arrangement, as shown in Fig. 10, reduces the local concentration of fuel agents by diffusing the fuel in front of the injection nozzles and as a result decreases the flame temperature. Since $\mathrm{NO}_{\mathrm{X}}$ production reactions are activated at high temperatures, this will significantly reduce the production of this type of pollutant in the flame front.

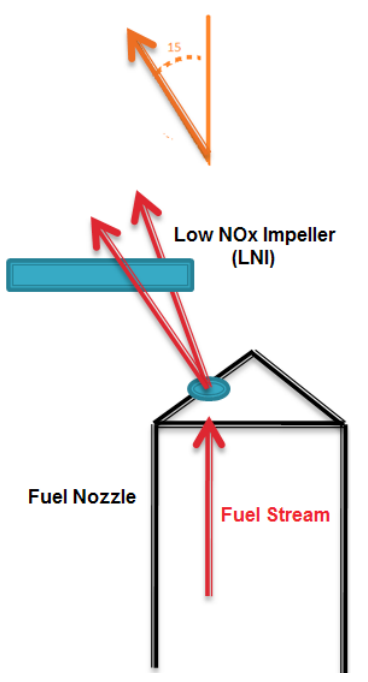

Fig. 10 LNI operation mechanism

MONTAZER GHAEM boiler fuel nozzles as shown in Fig. 11 are made in circular sections. The presence of discrete circle parts as fuel nozzles acts like LNI. As in the present numerical simulation, fuel nozzles have been modeled continuously in a rectangular cross-section with an area equal to the area of the nozzle holes, the estimated temperature at the flame front is more than the real value, which causes an error and, as a result, increasing in $\mathrm{NO}_{\mathrm{X}}$ prediction.

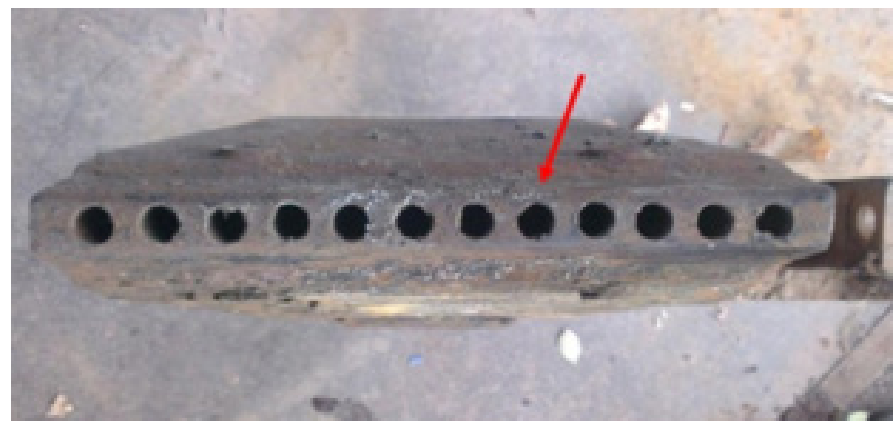

Fig. 11 MONTAZER GHAEM boiler fuel torches

2 Low $\underline{\mathrm{NO}}_{\mathrm{x}}$ Impeller 


\section{Conclusion}

The present paper has been developed with thermodynamic and numerical simulations of the MONTAZER GHAEM Power Plant. This study results suggested that some plans in the boiler structure should be considered to uniform the heat and temperature distribution in the furnace and prevent local accumulation of fuel and oxidizing agents. Installing the OFA system and, replacing existing burners with low- $\mathrm{NO}_{\mathrm{X}}$ and high-efficiency burners are the options that can meet these goals.

\section{Acknowledgement}

The authors would like to thank Monenco Iran Consulting Engineering Company for offering this research opportunity and for assistance during the course of this work.

\section{Nomenclature}

$\rho$ static pressure, Pascal density, $\mathrm{kg} / \mathrm{m}^{3}$ external body force, $\mathrm{N}$ gravity, $\mathrm{m} / \mathrm{s}^{2}$ stress tensor molecular viscosity, $\mathrm{kg} \mathrm{m} / \mathrm{s}$ unit tensor effective conductivity, W/m K sensible enthalpy of species $j$ diffusion flux of species $j$ heat of chemical reaction, and any other volumetric heat sources, $\mathrm{J}$ turbulence energy, $\mathrm{m}^{2} / \mathrm{s}^{2}$ stress tensor due to molecular viscosity turbulent dissipation rate $\mathrm{m}^{2} / \mathrm{s}^{3}$ turbulent Prandtl number for $k, 1.0$ turbulent Prandtl number for $\varepsilon, 1.2$ turbulence viscosity, $\mathrm{kg} \mathrm{m} / \mathrm{s}$ thermal expansion coefficient, $\mathrm{K}^{-1}$ velocity, $\mathrm{m} / \mathrm{s}$ velocity component along the direction $x_{j}, \mathrm{~m} / \mathrm{s}$ instant turbulence velocity on the direction $x_{i}, \mathrm{~m} / \mathrm{s}$ constant turbulent Prandtl number for energy component of the gravitational vector in the $i$ th direction, $\mathrm{m} / \mathrm{s}^{2}$ generation of turbulence kinetic energy due to buoyancy, $\mathrm{m}^{2} / \mathrm{s}^{2}$ contribution of the fluctuating dilatation in compressible turbulence to the overall dissipation rate modulus of the mean rate-of-strain tensor user defined source term user defined source term constant, 1.44 constant, 1.9 absorption coefficient, $\mathrm{m}^{-1}$ refractive index scattering coefficient, $\mathrm{m}^{-1}$ Stefan-Boltzmann constant $\left(5.67 \mathrm{E}-8 \mathrm{~W} / \mathrm{m}^{2} \mathrm{~K}^{-4}\right)$ local temperature, $\mathrm{K}$ local mass fraction of each species constant pressure specific heat of species $j$ net rate of production of species $i$ by chemical reactions

diffusion flux term of species $i$

diffusion coefficient for specie $i$ in the mixture thermal diffusion coefficient turbulent Schmidt number, 0.7 mass fraction of species $i$ within the fine structures after reacting over the time $\tau^{*}$ mass fraction of species $i$ in the fluid surrounding the fine structures mass fraction occupied by the fine structure regions volume fraction constant, 2.1377 kinematic viscosity $\mathrm{m}^{2} / \mathrm{s}$

\section{References}

[1] McKenty, F., Brais, N., Mifuji, M., Gravel, L., Sirois, Y. "Optimization of a Dual-Fuel Low-NO $\mathrm{N}_{\mathrm{X}}$ Combustion System for a Tangentially-Fired Utility Boiler Operating at a High Elevation." In: STAR Global Energy Forum Houston, USA, June 23-24, 2009.

[2] Modlinski, N. "Computational modeling of a utility boiler tangentiallyfired furnace retrofitted with swirl burners." Fuel Processing Technology. 91, pp. 1601-1608. 2010. https://doi.org/10.1016/j.fuproc.2010.06.008

[3] Fang, Q., Musa, A. A. B.,Wei, Y., Luo, Z., Zhou, H. "Numerical Simulation of Multifuel Combustion in a 200 MW Tangentially Fired Utility Boiler." Energy Fuels. 26, pp. 313-323. 2012. https://doi.org/10.1021/ef201149p

[4] Depman, A. "Stoker boiler CFD modeling improvements through alternative heat exchanger modeling." MSc Thesis, University of Iowa. 2014 http://ir.uiowa.edu/etd/4609

[5] Shi, L., Fu, Zh., Duan, X., Cheng, Ch., Shen, Y., Liu, B., Wang, R. "Influence of combustion system retrofit on $\mathrm{NO}_{\mathrm{X}}$ formation characteristics in a $300 \mathrm{MW}$ tangentially fired furnace." Applied Thermal Engineering, 98, pp. 766-777. 2016.

https://doi.org/10.1016/j.applthermaleng.2015.12.026

[6] Tang, G., Wu, B., Johnson, K., Kirk, A., Fu, D., Zhou, Ch. Q. "Numerical study of a tangentially fired boiler for reducing steam tube overheating." Applied Thermal Engineering. 102, pp. 261-271. 2016. https://doi.org/10.1016/j.applthermaleng.2016.03.104

[7] Sabounchi, A., Abadianzadeh, A. "Main air to secondary air ratio effect Evaluation of Shaheed Montazeri Power Station boiler in Isfahan by numerical simulation." In: 1st International Conference on New Research Achievements in Mechanics, Mechatronics and Biomechanics, Tehran, Iran, May 26, 2016. pp. 310-328. (in Persian)

[8] Saadati, E., Roushani, M. "Investigation of the effect of angle and speed of fuel injection burner on combustion parameters." In: 24th International Power System Conference, Tehran, Iran, 2009. pp. 155-162. (in Persian)

[9] Monenco Iran Consulting Engineers Co. "MONTAZER GHAEM Power Plant Boiler Upgrading report." Technical report. 2015. (in Persian) 
[10] Saadati, E., Zeynalabedini, M. "Fundamental and advanced CFD simulation with FLUENT and CFX." Pardad Petrodanesh firm (PETEC). 2015.(in Persian)

[11] Magnussen, B. F. "On the Structure of Turbulence and a Generalized Eddy Dissipation Concept for Chemical Reaction in Turbulent Flow." In: 19th Aerospace Sciences Meeting, St. Louis, USA 1981. https://doi.org/10.2514/6.1981-42

[12] Aminian, J., Shahhosseini, S., Bayar, M. "Investigation of Temperature and Flow Fields in an Alternative Design of Industrial Cracking Furnaces Using CFD." Iranian Journal of Chemical Engineering. 7(3), pp. 61-73. 2010.
[13] FLUENT. "FLUENT 6.3 User's Guide." Lebanon, USA. 2006.

[14] Management of MONTAZER GHAEM Power Generation Co. "Steam Boiler specifications report." Technical report. 2015. (in Persian)

[15] Mujtabaie, M. M. "MONTAZER GHAEM Steam Power Plant." Management of MONTAZER GHAEM Power Generation Co. 2003.(in Persian)

[16] Niro Research Institute. "MONTAZER GHAEM Power visit report." Technical report. 2015. (in Persian) 